\title{
INTERNACIONALIZAÇÃO DA EDUCAÇÃO SUPERIOR COMO PROCESSO DE MANUTENÇÃO HEGEMÔNICA: A UNIVERSIDADE ABERTA DO BRASIL E 0 PROCESSO DE BOLONHA
}

RESUMO: Contraditoriamente, a educação tem ocupado papel fundamental na formação de capital humano e de um projeto de emancipação. Nesse campo, de intensa disputa, a educação serve, hegemonicamente, ao capital que, contemporaneamente, se apresenta de forma financeirizada. Aliado a essa dinâmica, o processo de internacionalização da educação tem servido para disseminação de um modelo que necessita de consensos ativos. O caso mais evidente e atual dessa submissão, no que diz respeito ao Ensino Superior (ES), é o Processo de Bolonha (PB) que, ao implementar um modelo internacional de ES, influenciou políticas educacionais brasileiras, como é o caso da Universidade Aberta do Brasil, objeto de pesquisa deste estudo. A partir de análise documental, foi possível compreender como ocorreu a incorporação dos princípios de internacionalização do ES no contexto brasileiro. Além disso, percebeu-se que as categorias participação e responsabilização, qualidade e resultados, e estandardização, tornam-se cruciais para a implantação das políticas de ES no contexto da mundialização do capital.

PALAVRAS-CHAVE: Universidade Aberta do Brasil, Internacionalização da Educação, Ensino Superior.

\section{INTERNATIONALIZATION OF HIGHER EDUCATION AS A HEGEMONIC MAINTENANCE PROCESS: THE OPEN UNIVERSITY OF BRAZIL AND THE BOLOGNA PROCESS}

\begin{abstract}
Education has played a contradictory but fundamental role in the formation of human capital and in the project of emancipation. In this field, of intense quarrel, the education serves, hegemonic, the capital that, contemporaneously, presents itself in a financialized way. Allied to this dynamic, the internationalization process of education has served to disseminate a model that needs active consensus. The most obvious and current case of this submission, in higher education (HS), is the Bologna Process (BP), which, when implementing an international model of HS, influenced Brazilian educational policies, as is the case of the Open University of Brazil, study object of this research. Through documentary analysis, we understood how the incorporation
\end{abstract}

Prof. Me. Guilherme Afonso Monteiro de Barros Marins

guilherme.afonso.marins@ gmail.com

Docente da Rede Municipal de Educação de Campo Grande

Prof. Dr. Fabiano Antonio dos Santos

santos.fabianoad@gmail.com Docente do Programa de PósGraduação em Educação da Universidade Federal de Mato Grosso do Sul 
of the internationalization principles of Brazilian's HS context has taken place. We perceived that the categories participation and accountability; quality and results; and standardization become crucial to the implementation of higher education policies in the context of the capital globalization.

KEYWORDS: Open University of Brazil, Internationalization of Education, Higher Education.

\section{INTRODUÇÃO}

O Brasil ingressou, definitivamente, no terreno neoliberal a partir dos anos 1990, com a reforma do Estado brasileiro. Na proposta de reforma, o, então, ministro Bresser-Pereira passou a defender que o Estado deveria delimitar, mais claramente, suas fronteiras com o setor privado e as instituições não governamentais, alegando que a gestão pública era atrasada e burocrática. Com isso, foram propostas algumas mudanças significativas. Uma delas foi que o Estado fosse organizado a partir de quatro setores: núcleo estratégico; atividades exclusivas do Estado; atividades ou serviços não exclusivos do Estado; e produção de bens e serviços para o mercado.

As universidades públicas pertenceriam ao núcleo não exclusivo do Estado, sendo os serviços, desse núcleo, oferecidos também pelo setor privado e setor público não-estatal (uma categoria criada que se aproximava das propostas de terceira via defendida por Anthony Giddens na Inglaterra). O termo; 'público-não-estatal', significa, segundo Giddens, uma propriedade "pública, no sentido de que se deve dedicar ao interesse 'público', de que não visa ao lucro, 'não-estatal' porque não fazem parte do aparelho do Estado” (BRESSER-PEREIRA, 1999, p. 35). A nova categoria de serviços oferecidos estaria sob tutela do Estado, mas aberta ao investimento de empresas privadas e, principalmente, de organizações sociais. Viu-se a multiplicação de organizações não governamentais, ocupando o papel do Estado na gestão da educação pública brasileira, no entanto, sempre com o apoio financeiro dos fundos públicos.

Essas novas características da universidade pública brasileira acompanham um movimento mais amplo de financeirização da economia e, consequentemente, de mercantilização da educação. Diante disso, neste estudo, apresenta-se como o Processo de Bolonha (PB) tem disseminado esse novo modelo de universidade pautado no mercado de 
serviços. Utilizou-se, como referência, a Universidade Aberta do Brasil (UAB) por representar a modalidade de ensino que mais tem se expandido no Brasil: a educação a distância (EaD).

Tem-se como hipótese, o fato de que é justamente por essa característica que a UAB ocupou lugar central na propagação de práticas vinculadas ao novo modelo de ensino superior proposto pelo PB. A saber: ensino pautado em atividades que homogeneízam os currículos e, consequentemente, a formação acadêmica/profissional; atividades desenvolvidas em nome de uma suposta qualidade que se vincula à mensuração por meio de avaliações; e participação de atores dos mais diversos setores da sociedade como forma de legitimar a implementação do modelo de ensino superior baseado em uma perspectiva gerencial e pragmática.

\section{MUNDIALIZAÇÃO DO CAPITAL E INTERNACIONALIZAÇÃO DA EDUCAÇÃO}

A característica mais marcante do Estado capitalista é a produção de bens e serviços com a geração e acumulação de riquezas concentradas quase que, exclusivamente, sob as demandas diretas da classe burguesa.

Chesnais (1996) mostra que, ao longo do seu percurso histórico, o capitalismo foi se modificando para atender às demandas produtivas da classe burguesa, iniciando com o capitalismo concorrencial e chegando ao capitalismo monopolista. Concomitantemente, essa transformação gerou o capital mercadoria, posteriormente, o capital industrial e comercial, e, então, o capital financeiro. A principal diferença entre os três, segundo o autor, é que nas fases de mercadoria e industrial e comercial, o capital é fruto da relação de trabalho do homem com a natureza, ou seja, capital produtivo. Já a financeirização do capital é fruto da relação rentista do próprio capital e dinheiro. Em outras palavras, é ‘dinheiro fazendo dinheiro', sob as possibilidades de geração da rentabilidade de investimentos lucrativos por meio de instituições bancárias, bolsas de valores e Organismos Multilaterais (OM).

Neste cenário, a educação superior constata sua importância em dois sentidos: primeiro, como serviços que se associam à lógica rentista da financeirização econômica e, segundo, por se constituir como formadora dos novos sujeitos que vão se inserir no mundo do trabalho. 
[...] processos contíguos vão conformar as propostas e demandas empresariais no campo da formação da força de trabalho (tanto em sentindo amplo quanto restrito), na medida em que, por um lado, a escolarização formal do trabalhador de chão de fábrica vai passar a ser vista como requisito cada vez mais necessário em face do objetivo de obtenção de ganhos de produtividade do trabalho e qualidade dos produtos; e, por outro lado, o estabelecimento de um novo padrão nas relações entre os campos do capital e do trabalho em nosso país que venha a significar a superação do aspecto conflituoso que caracterizou e continua majoritariamente caracterizando tais relações torna-se uma intenção central das diretrizes e ações elaboradas pelas instâncias de representação/organização empresariais. O campo da educação, assim, vai paulatinamente se tornar, ao longo dos últimos anos, em objeto de cada vez maior atenção por parte da burguesia industrial brasileira. (ANDRADE, 2008, p. 60).

Bianchetti (1996, p. 94) aponta o interesse diretivo na educação pela classe dominante, pois, as políticas educacionais propostas pelos governos são conformadoras "[...] de uma estrutura educacional que seja veículo de efetivação das exigências do modelo social”.

O modelo de educação promovido pelo PB, e assumido pela UAB, faz parte de um movimento global e constitui-se de uma agenda internacional para a educação em todos os níveis.

Dale (2004, p. 446) propõe analisar esse movimento a partir da constituição de uma “Agenda Global Estruturada para Educação”, em que o uso da linguagem, na disseminação das ideias de defensores da 'educação globalizada', evoca termos como "normas”, “convenções”, "costumes" e "padrões", porém, não possuem especificidades. Ainda de acordo com o autor, as diferentes conotações dessas terminologias pelo mundo são pouco detalhadas e confundem-se com processo e/ou produto. No entanto, sempre denotam

[...] "padrões mundiais", implicando aparentemente uma medida de qualidade; referências a um "padrão educacional correto", implicando aparentemente um critério de sucesso; e aos "padrões dominantes de propriedade educacional", implicando aparentemente algum tipo de norma (DALE, 2004, p. 442).

A centralidade e o olhar de mundo que Dale (2004) toma como partida para caracterizar a agenda mundializada para a educação e, ao mesmo tempo, a crítica do currículo globalizado estão na percepção do capitalismo como fonte causal das mudanças do mundo, conduzidas pelo lucro. 
Nesse aspecto, o Estado representa importante aliado na medida em que repassa tarefas centrais, à sociedade civil, que deveriam fazer parte de suas obrigações. A própria educação superior passa a compor o rol de serviços sob responsabilidade de outras instituições que não exclusivamente o Estado. Dois fatores corroboram para a descentralização das atividades do Estado: um interno (de cada país) - com ênfase na participação da sociedade civil, e outro internacional, que incentiva o conceito de "governança sem governo" (DALE, 2004).

O termo governança teve sua gênese durante os anos 1990 e seu principal difusor foi o Banco Mundial (BM) (BORES, 2003). Para o BM, governança significa “[...] a maneira pela qual o poder é exercido na administração dos recursos econômicos e sociais do país, com vistas ao desenvolvimento" (BANCO MUNDIAL, 1992). Todavia, o agente que deve conduzir a "maneira de exercer o poder na/pela administração", conforme defendido pelo BM e outros OM, não é o Estado, como ente central, e sim toda a sociedade civil conjunta, visando uma mudança na instituição organizadora da administração pública. A mudança no exercício administrativo pauta-se por uma estratégia não somente global de reestruturações macroeconômicas, mas, também, de stricto sensu (BORES, 2003, p. 125).

\section{PROCESSO DE BOLONHA: MODELO DE INSPIRAÇÃO PARA UMA NOVA PERSPECTIVA DE UNIVERSIDADE MUNDIALIZADA POR MEIO DA UAB}

O PB, segundo Ruiz (2004), foi a iniciativa mais importante que a Europa desenvolveu na área da educação superior. É também um exemplo de como a dinâmica da mundialização e internacionalização das políticas educacionais acontece. Tal processo se refere a um conjunto de acordos firmados para a educação superior, realizado por países europeus entre si, que busca consolidar o Espaço Europeu de Ensino Superior (EEES).

Em 1998, foi realizado, oficialmente, na Universidade de Sorbonne, em Paris, um encontro com os ministros da educação ${ }^{1}$ da Alemanha, da França, da Itália e do Reino Unido. A reunião dirigiu-se aos países com

\footnotetext{
1 Foi escolhido, de maneira sintética, o termo "ministro da educação", porém, as corretas denominações dos cargos, bem como seus titulares na época, são: Ministro para Educação, Pesquisa e Tecnologia da França (Claude Allegre); Ministro da Instrução Pública, Universitária e Pesquisa da Itália (Luigi Berlinguer); Ministra da Educação Superior do Reino Unido (Tessa Blackstone); Ministro da Educação, Ciência, Pesquisa e Tecnologia da Alemanha (Jürgen Rüttgers) (DECLARAÇÃO DE SORBONNE, 1998).
} 
maior interesse pela criação de um espaço de educação superior comum para toda a Europa (LIMA; AZEVEDO; CATANI, 2008).

A Declaração de Sorbonne ${ }^{2}$, resultado do encontro de 1998, assinada pelos ministros, foi o início da materialização de um processo voltado ao ensino superior do sistema europeu e, posteriormente, de ampliação globalizada de seus ideais.

Devemos fortalecer e construir o nosso continente sobre as dimensões intelectuais, culturais, sociais e técnicas. Estas têm, em grande parte, sido definidas pelas universidades, que continuam a ter um papel fundamental no seu desenvolvimento (DECLARAÇÃO DE SORBONNE, 1998).

A proposta visava promover "esforços vigorosos na abolição das barreiras e no desenvolvimento de um panorama de ensino, com o intuito de promover a mobilidade e uma cooperação cada vez mais estreita”, além de garantir "originalidade e flexibilidade, reconhecimento internacional do diploma, validação de créditos internacionais, harmonização progressiva das estruturas” (DECLARAÇÃO DE SORBONNE, 1998, [s/p]).

Para Lima, Azevedo e Catani (2008, pp. 10-11), a promoção do sistema europeu de educação superior tem o interesse de torná-lo

[...] fortemente competitivo face, sobretudo, aos Estados Unidos da América, designadamente pela atração de estudantes de outros continentes, designadamente o asiático. O texto da Declaração de Bolonha não se revela nada enigmático quanto à opção pelo princípio da competitividade em termos não só de emulação, de eficiência e de financiamento, mas também de lógica mercantil, assumindo com clareza a ideia da centralidade da Europa no fornecimento de serviços educativos, de resto de matiz assumidamente etnocêntrico [...].

Bianchetti (2015) especifica que a declaração contém elementos de um espectro econômico de unificação da moeda euro e da União Europeia (UE), em busca da centralidade que a Europa já ocupou em outros tempos no mundo.

2 A cada encontro ministerial entre os membros da União Européia, que aderiram ao Processo de Bolonha, elaborou-se um documento (declaração/comunicado), a fim de registrar as ações e os objetivos a serem, ou que foram, realizados pelos signatários. Cada encontro carrega consigo o nome da cidade sede da reunião, a saber: Declaração de Sorbonne (Paris) 1998, Declaração de Bolonha (Itália) - 1999, Comunicado de Praga (República Checa) - 2001, Comunicado de Berlim (Alemanha) - 2003, Comunicado de Berger (Noruega) - 2005, Comunicado de Londres (Inglaterra) - 2007, Comunicado de Louvaine (Bélgica) - 2009 e Comunicado de Budapeste (Hungria) - 2010. 
De 1998 até 2009, as declarações e os comunicados realizados nos encontros ministeriais de educação superior demarcaram a necessidade do fortalecimento de

[...] um Espaço Europeu de Ensino Superior - que viabilize a internacionalização das universidades, facilite a mobilidade de alunos e docentes, promova a empregabilidade dos cidadãos europeus e concorra para o desenvolvimento econômico, social e humano da Europa - a consolidação e enriquecimento da cidadania europeia e o aumento da competitividade com outros sistemas de ensino do mundo [...] (MORGADO, 2009, p. 50).

Assim, o PB se tornou um modelo de inspiração de propostas diversas para o ensino superior em todo o mundo. Neste estudo, ressalta-se como esse programa de internacionalização vem sendo aplicado no Brasil em diversos âmbitos da educação superior. Em particular, a criação da Universidade Aberta do Brasil (UAB), com suas devidas particularidades, assumiu aspectos centrais daquele modelo europeu: a ênfase na participação e responsabilização dos sujeitos; a priorização na qualidade associada aos resultados mensuráveis; e a padronização de práticas e conteúdos curriculares.

A implantação da UAB, como programa público de expansão do ensino superior, aconteceu no evento intitulado Fórum das Estatais pela Educação, no ano de 2005. Todavia, o evento propriamente dito foi criado em 2004, com o subtítulo Diálogo para Cidadania e Inclusão, e propôs, em seu relatório, como um dos objetivos, a reforma da educação superior.

\section{O principal objetivo da criação do fórum foi}

[...] potencializar as políticas públicas na educação promovidas pelo governo federal e pelo MEC, através da interação entre sociedade civil brasileira, empresários, trabalhadores e organismos internacionais [...] visando a construção de um novo modelo de desenvolvimento para o país. [...] definição de um conjunto de ações desafiadoras para a solução dos problemas e aproveitamentos das oportunidades, tendo em vista os objetivos do programa (BRASIL, 2004, [ ], grifos nossos).

Em fevereiro de 2005, a temática do Fórum das Estatais para a Educação foi: Universidade Aberta do Brasil. Nesse encontro, a UAB se caracterizou como política pensada, articulada e materializada juntamente com a sociedade civil. Em 2006, a UAB se tornou legalmente 
amparada pelo Decreto presidencial $\mathrm{n}^{\circ} 5.800$, de 08 de junho de 2006 (BRASIL, 2006), como programa político de expansão do ensino superior.

Com a criação da UAB, os seguintes objetivos deveriam ser cumpridos:

I - oferecer, prioritariamente, cursos de licenciatura e de formação inicial e continuada de professores da educação básica;

II - oferecer cursos superiores para capacitação de dirigentes, gestores e trabalhadores em educação básica dos Estados, do Distrito Federal e dos Municípios;

III - oferecer cursos superiores nas diferentes áreas do conhecimento;

IV - ampliar o acesso à educação superior pública;

$\mathrm{V}$ - reduzir as desigualdades de oferta de ensino superior entre as diferentes regiões do país;

VI - estabelecer amplo sistema nacional de educação superior a distância; e

VII - fomentar o desenvolvimento institucional para a modalidade de educação a distância, bem como a pesquisa em metodologias inovadoras de ensino superior apoiadas em tecnologias de informação e comunicação (BRASIL, 2006, grifos nossos).

Com tais metas, o governo, por intermédio da Secretaria de Educação a Distância do MEC, intentou a formação universitária de $30 \%$ dos estudantes brasileiros na modalidade, para interiorizar a educação de nível superior nas regiões onde as estruturas físicas não chegavam (ZUIN, 2006). A proposição da UAB respondeu ao plano de expansão do ensino previsto no Plano de Desenvolvimento da Educação (PDE).

A UAB dialoga, assim, com objetivos do PNE: "Ampliar, a partir da colaboração da União, dos estados e dos municípios, os programas de formação em serviço que assegurem a todos os professores a possibilidade de adquirir a qualificação mínima exigida pela LDB, observando as diretrizes e os parâmetros curriculares" e "Desenvolver programas de educação a distância que possam ser utilizados também em cursos semipresenciais modulares, de forma a tornar possível o cumprimento da meta anterior" (BRASIL, 2007a, p. 17).

A participação de diferentes setores, na concretização do Fórum das Estatais, marca um dos aspectos de maior aproximação entre o PB e a UAB. Trata-se das estratégias de convencimento, tão necessárias para que a implementação de políticas de tamanhas proporções e de impactos tão significativos seja aceita sem grandes problemas. 
Ainda sobre o PB como fonte inspiradora de uma nova forma de fazer a gestão do ensino superior no Brasil, percebe-se como a UAB, por meio do EaD, consolida-se como potente ferramenta de disseminação da nova gestão e organização do ensino superior. Essa forma de gestão e organização vai se materializando como exemplo de sucesso, justamente, por seu grande alcance em termos numéricos, uma das características do ensino a distância no país.

\section{OS PRINCÍPIOS ORIENTADORES DA INTERNACIONALIZAÇÃO DO ENSINO SUPERIOR E A UAB}

Considerando o PB como importante movimento indutor do funcionamento do ensino superior em todo o mundo, a seguir, apresenta-se uma análise dos principais documentos desse processo, bem como os registros orientadores da UAB, de modo a poder confrontá-los. A partir do cotejamento desses materiais, destacam-se os três princípios que expressam as relações entre o projeto de universidade e, portanto, de educação superior mundializada, promovida pelo PB e pela UAB.

\section{Participação e responsabilização: a formação do consenso ativo}

As propostas elaboradas pelo PB e pela UAB são muito semelhantes. Ambas contaram com algo que Gramsci (2011) denominou de consenso ativo, ou seja, com a participação ativa dos sujeitos. Tanto no caso da UAB como do PB, houve um grande acordo envolvendo classes distintas: empresários, trabalhadores, organismos multilaterais, empresas estatais e organizações não governamentais. Tal acordo resultou na amálgama necessária para cimentar as propostas em seus respectivos contextos, sem que grandes enfrentamentos fossem impeditivos de sua efetivação.

No processo europeu, isso ficou claro quando a União Europeia Universitária foi convidada a participar do PB. Em prol desse grupo, algumas metas foram inseridas, como a participação efetiva dos estudantes (COMUNICADO DE PRAGA, 2001, $[s / p]$ ). Ao mesmo tempo, a UNESCO e o Business Europe debatem o PB e incluem as suas intenções. Essa “junção” de interesses, de instituições distintas, se mostra convergente na ampliação do capitalismo. 
De um lado, tem-se as "empresas" (instituições de ensino superior e demais organizações) que, pressionadas pelo capital, precisam aumentar seu mercado interno e externo para se manterem operantes no sistema econômico, sem, contudo, sofrerem muitas perdas nas suas taxas de retorno. As Instituições de Ensino Superior (IES) europeias necessitam maior número de alunos, e as empresas precisam de trabalhadores minimamente capacitados para desempenharem suas funções laborais, em um tempo curto de formação, - aumentando, assim, um rol de possibilidades na escolha de possíveis candidatos aos empregos - mas, ao mesmo tempo, precarizando o trabalho de maneira geral.

Por outro lado, tem-se os estudantes que, possivelmente, estabelecem uma relação linear entre formação acadêmica e melhoria nas condições de vida, voltados muitas vezes, ao objetivo da empregabilidade. Desse modo, monta-se um cenário perfeito para que os agentes envolvidos manifestem o mesmo discurso em defesa da política de internacionalização do ensino superior.

No programa da UAB, pode-se destacar dois momentos que envolvem fortemente a criação do consenso ativo e da responsabilização. Um se baseia na política de "expansão do ensino superior”, e o outro, no "acesso ao conhecimento", afinal, nenhuma instituição ou sujeito é contrário a ambos os casos. Assim, os discursos possuem características semelhantes para diferentes agentes.

Desde a sua formação, em 2005, instituições de diferentes segmentos foram convidadas para criar o programa UAB. A saber: empresas estatais, como a Embrapa, Infraero, BNDES, a Associação Nacional dos Dirigentes das Instituições Federais do Ensino Superior (ANDIFES) e o Ministério da Educação (MEC). Ressalta-se que determinadas empresas estatais, como Banco do Brasil, Eletrobras (proprietária de 50\% da Itaipu) e Petrobras, também participntes do fórum, possuem capital aberto e suas ações são negociadas na bolsa de valores ${ }^{3}$.

O Fórum das Estatais de 2005, cuja temática foi Universidade Aberta do Brasil, teve como objetivo central o desenvolvimento de uma fundação de fomento ao programa, isto é, a “[...] criação de uma fundação de direito privado, sem finalidades lucrativas, denominada FUNDAÇÃO DE FOMENTO À UNIVERSIDADE ABERTA DO BRASIL” (BRASIL, 2005, p. 3). Com isso, as seguintes missões deveriam ser alcançadas:

3 Informações obtidas por meio do site oficial da Bovespa e da Itaipu, respectivamente em: $<$ http://www.bmfbovespa.com.br> e <https://www.itaipu.gov.br>. 
1) Criação de Programa de Bolsas de Pesquisa em Educação Aberta e a Distância;

2) Organização de Consórcios Públicos nos Estados envolvendo os três níveis governamentais (federal, estadual e municipal) e as Universidades Públicas Federais;

3) Consolidação das Bases da Universidade Aberta do Brasil (UAB) (BRASIL, 2005, p. 1, grifos nossos).

Todavia, tal fundação não se limitou à participação de agentes/ instituições públicos apenas. As organizações que fazem parte desse projeto mesclam-se entre públicas e privadas, podendo-se dar ênfase ao conglomerado da representação industrial brasileira pela Confederação Nacional das Indústrias (CNI) ${ }^{4}$. Assim, o conselho gestor da fundação de fomento tem representatividade da seguinte forma:

À guisa de motivação para discussão, propõe-se modelo de estruturação para a FUNDAÇÃO, cujos membros do Conselho Gestor seriam: um representante de cada uma das EEs [Empresas Estatais] proponentes da FUNDAÇÃO, três representantes do MEC (Secretários de Educação a Distância, de Educação Superior e o Presidente da Coordenação de Aperfeiçoamento de Pessoal de Nível Superior - CAPES), três reitores indicados pela ANDIFES, um representante do Consórcio Público de cada Estado, um representante da Confederação Nacional da Indústria - CNI, um representante da Rede de Universidades Públicas - UNIREDE e um representante da Associação Brasileira de Educação a Distância - ABED (BRASIL, 2005, p. 3, grifos nossos).

Essa informação indica, pela necessidade comercial/ mercantil, que os objetivos das empresas estão voltados àqueles vinculados ao capital financeiro. A defesa do papel do Estado, em congregar a sociedade civil para ampliar o espectro da política, aparece no documento do Fórum das Estatais de 2004: "A partir do papel estrutural do Estado na indução do desenvolvimento, compreende-se como tarefa de todos os agentes institucionais uma articulação orgânica em torno de políticas de inclusão e justiça social” (BRASIL, 2004, p. 1, grifos nossos).

4 A CNI é a representação máxima das Federações das Indústrias Estaduais no Brasil. Lembrando que algumas agências do sistema S, para a indústria, como o SESI (Serviço Social da Indústria) e o SENAI (Serviço Nacional de Aprendizagem Industrial), constantemente são escoIhidos para realizarem atividades "paraestatais", serviços públicos para a população em geral, seguindo a moda da Terceira Via. As atividades públicas e estatais são diluídas e entregues aos membros da sociedade civil. 


\section{Qualidade e resultado}

Certamente, o conceito de qualidade é um dos pontos mais importantes e estratégicos para a implementação de mudanças estruturais na educação. Nas políticas contemporâneas, esse conceito amplamente aceito se associa aos resultados. Dessa forma, a qualidade da educação será alcançada na medida em que os resultados mensuráveis forem atingidos.

A questão da qualidade se destacou em todas as etapas do PB, desde a sua declaração, em 1999, até o Comunicado de Leuven/Louvain-la-Neuve, em 2009. A qualidade e sua garantia ocupam centralidade nas discussões e nos documentos do PB.

Os ministros reconheceram o papel vital que os sistemas de garantia de qualidade desempenham, assegurando padrões de qualidade elevados e facilitando a comparabilidade de qualificações ao longo da Europa. Encorajaram também a cooperação mais estreita entre as redes de reconhecimento e de garantia de qualidade e enfatizaram a necessidade de cooperação europeia estreita e de confiança mútua na aceitação dos sistemas de garantia de qualidade nacionais (COMUNICADO DE PRAGA, $[s / p]$, 2001, tradução nossa).

Nós adotamos as normas e diretrizes para a garantia da qualidade na Área de Educação Superior Europeia, tal como proposto pela Associação Europeia para a Garantia da Qualidade no Ensino Superior. Comprometemo-nos a introduzir o modelo proposto para avaliação dos pares das agências de garantia da qualidade a nível nacional, respeitando as diretrizes e os critérios comumente aceitos. Congratulamo-nos com o princípio de um registro europeu de agências de garantia da qualidade com base na avaliação nacional (COMUNICADO DE BERGEN, $[s / p]$, 2005, tradução nossa).

As normas e diretrizes para a garantia da qualidade adotadas em Bergen pela Associação Europeia de Ensino Superior têm sido um poderoso motor da mudança em relação à garantia de qualidade. (COMUNICADO DE LONDRES, $[s / p], 2007$, tradução nossa).

Como examina Catani (2010), a qualidade é utilizada como apontamento para a legitimidade da excelência. Assim, observa-se que o conceito de qualidade serve como slogan fundamental para aproximar discursos, claramente, opostos como os proferidos por sindicatos e OM, por exemplo. Tanto no PB como na UAB, o conceito qualidade estimula uma visão gerencial de educação, baseada em mecanismos de avaliação estandardizados. 
O documento referendado para se discutir qualidade no sistema UAB, posto no próprio Guia de Orientações Básicas sobre o Sistema Universidade Aberta do Brasil, elaborado pela UAB e CAPES, intitula-se Referência de Qualidade para Educação Superior a Distância. No documento, a qualidade é pautada com maior ênfase pelos "[...] resultados avaliativos realizados pelo MEC em múltiplos programas de educação a distância em andamento no país, sempre na busca de uma configuração que atenda aos requisitos de qualidade que todos almejamos" (BRASIL, 2007b, p. 4).

Como foi possível observar nos documentos do processo e das instituições que o envolvem, há o entrelaçamento da qualidade com os resultados alcançados. No caso do PB, tal relação se refere à mobilidade estudantil, professoral e de equipes de trabalho entre as instituições de ensino, à criação de créditos educacionais de equivalência entre as IES, à empregabilidade e importância da compreensão do conhecimento prévio e da educação continuada que auxilia no constructo do aprendizado ao longo da vida, pautado em uma sociedade em constantes mudanças, que são mediadas pelos interesses do mercado.

[...] as instituições têm uma necessidade de continuar a desenvolver as suas estratégias e atividades no domínio da aprendizagem ao longo da vida, e pensar na aprendizagem ao longo da vida como uma missão principal. Mais uma vez, um maior diálogo com os empregadores é necessário, pois, os cursos universitários, em todos os níveis, são para atender as necessidades de uma sociedade em mudança e da economia em que o conhecimento se torna rapidamente obsoleto, portanto, fazem-se necessários constantes treinamentos e reciclagens (EUA, 2007, pp. 78-79, tradução e grifos nossos).

Já na UAB, a relação qualidade e resultado é evocada em alguns momentos para a legitimação da política e associada à eficiência de gestão, à institucionalização do modelo $\mathrm{EaD}$, bem como, às condições de estrutura para o funcionamento da UAB.

No Guia de Orientações Básicas sobre o Sistema UAB, há oito eixos de avaliação para a qualidade: 1) Concepção de educação e currículo no processo de ensino e aprendizagem; 2) Sistemas de Comunicação; 3) Material didático; 4) Avaliação; 5) Equipe multidisciplinar; 6) Infraestrutura de apoio; 7) Gestão Acadêmico-Administrativa; e 8) Sustentabilidade financeira (BRASIL, 2007a). Esses eixos corroboram um olhar gerencialista e superficial quando tratam da qualidade, além de expressarem claramente, assim como no PB, a padronização de práticas 
corporativas via qualidade e resultado. Além disso, ainda preocupam-se em estabelecer o know-how (como fazer) em detrimento da educação propedêutica e da evocação para a apreensão do conhecimento que busque a interpretação da realidade. Essa característica é muito próxima da ideia defendida no $\mathrm{PB}$, quanto à necessidade do conhecimento pragmático para a ação imediata - alicerce do lifelong learning.

\section{Padronização}

A padronização, conhecida também como estandardização, defende em seu discurso uma "[...] universalidade demasiadamente abstrata, que termina por desconhecer as especificidades dos diferentes objetos" (LIMA, 1996, p. 6).

Os objetivos do PB e das UAB estão intimamente relacionados à educação mercadoria, por isso, buscam padronizá-la como um bem a ser consumido dentro das relações de produção capitalista.

A União Europeia, por meio do Jornal Oficial da União Europeia, no item Conclusões do Conselho sobre a Dimensão Global do Ensino Superior Europeu - edição de 31/01/2014 - considerou a internacionalização da educação superior.

A presença ativa de pessoal, investigadores e estudantes de diversos países nos estabelecimentos europeus de ensino superior, o apoio financeiro e organizativo prestado à mobilidade internacional tanto dos estudantes como do pessoal, e o crescente esforço envidado para internacionalizar os currículos pode ajudar os alunos a adquirir competências relevantes para o mercado de trabalho mundial (UE, 2014, p. 3, grifos nossos).

No mesmo documento, a UE congratulou as iniciativas de programas de internacionalização da educação pelos “[...] esforços para aumentar a atratividade e promover a diversidade do ensino superior europeu em todo o mundo" (UE, 2014, p. 5).

Em comparação com o modelo europeu, nota-se que, no programa brasileiro, não há distinção, quanto ao seu auxílio, na ampliação das forças produtivas capitalistas através da educação. Desse modo, é essencial padronizar suas ações.

A estrutura básica da UAB e dos Consórcios deve se assemelhar mais a uma "fábrica", enfatizando a alta produção de cursos (planejamento 
curricular e pedagógico; a preparação de roteiros de cursos; a produção audiovisual; os textos de acompanhamento; o atendimento a suporte ao aluno; a avaliação do aluno e do curso), via várias formas tecnológicas (BRASIL, 2005, p. 10).

Embora exista uma distinção entre os programas brasileiro e europeu, no que se refere às dinâmicas sociais que os cercam e aos seus níveis de desenvolvimento econômico, e principalmente industrial, nas regiões do mundo que programas como estes se materializam, intensifica-se a ideia de que a estandardização desses programas é alicerce intrínseco para maior controle de suas propostas e melhor mensuração dos seus objetivos. Com isso, todo o processo educativo é padronizado. Há uma tendência natural, dentro dessa perspectiva homogeneizante, de um protótipo institucionalizado a ser seguido.

A padronização, no PB, se caracteriza mais fortemente pela criação do Espaço de Ensino Superior Europeu Unificado, que fomenta o conhecimento sem fronteira, coerente com o mundo globalizado e suas ferramentas para assegurar tal padronização.

Nessa lógica de internacionalização proposta, os créditos acadêmicos são organizados com base no European Credit Transfer System (ECTS), que favorece, conforme Bianchetti (2015), a transferência de alunos entre as IES, atraindo mais matrículas estrangeiras e mercantilizando as instituições que aderiram ao PB. O apelo comercial, por meio da padronização, torna-se muito efetivo para a clientela, que tem a possibilidade de cursar uma graduação em três ou quatro países que dividem o mesmo processo operacional, aumentando assim as chances de matrículas do alunado. Os ECTS, de acordo com Liria e García (2009), compõem a criação do euro (moeda) do mundo acadêmico, realizado à sua forma e semelhança. Segundo os autores, o sistema de crédito patenteia o processo de monetarização do PB pela utilização da palavra "crédito" e pelo uso equitativo nas disciplinas e nos projetos realizados entre as IES.

Outra aplicação da estandardização na política educacional do PB é encontrada na estrutura do ensino superior e de pós-graduação. Desde o Comunicado de Bolonha, em 1999, até o Comunicado de Berlim, em 2003, foi mantido como meta o nivelamento em três ciclos entre a licenciatura e o doutorado, prevendo "[...] a estruturação dos currículos universitários em três graus sequenciais de estudos (Licenciatura, Mestrado, Doutoramento)" (IACOBUCCI, 2012, p. 1, tradução nossa). 
Para cada ciclo, há um número específico de ECTS: na licenciatura, há 180 créditos para cursos de três anos e 240 créditos para cursos de quatro anos; já para o mestrado, há 120 créditos $^{5}$. A adoção do sistema de ciclos serve para os fins e objetivos da "compatibilidade" dos títulos acadêmicos europeus, fundamentais, por sua vez, para a meta (incluída nos princípios básicos da União Europeia) “[...] da liberdade de movimento de estudantes e trabalhadores no continente” (IACOBUCCI, 2012, p. 27, tradução nossa). Essa proposta foi aceita com rapidez pelos ministros europeus, pois o sistema de créditos e ciclos concorreu para a diminuição considerável do tempo de formação nos cursos.

[...] durante a década de 1990, alguns governantes europeus começaram a identificar, na estrutura dos currículos acadêmicos do próprio país (diferente da dos demais países extras europeus que já tinham adotado um esquema baseado sobre ciclos), a causa dos problemas do sistema nacional de ensino superior, nomeadamente: a longa duração dos estudos (amiúde 7-8 anos para cursos de duração nominal de 5 anos) e, consequentemente, os custos (públicos e privados) elevados, a dificuldade na revalidação dos títulos a nível internacional (e portanto o decréscimo de estudantes estrangeiros), as taxas de abandono elevadas, os elevados graus de desemprego entre graduados, a falta de flexibilidade e adaptabilidade dos programas de estudo (IACOBUCCI, 2012, p. 27, tradução nossa).

A retórica adotada pelos países signatários do PB, na adoção desse sistema de créditos e ciclos mais flexíveis e adaptáveis, concomitante a elevação de custos, diante da desistência dos alunos das IES e da questão da educação para empregabilidade, é muito próxima da retórica das IES brasileiras, por estimularem a educação na modalidade a distância e da própria UAB.

O desafio se resume no desenvolvimento de uma grande capacidade adaptativa aliada à estruturas flexíveis - dadas as mudanças profundas e rápidas - de modo a se perpetuar a competitividade no ambiente global no presente e futuro. Para tanto, planejamento é essencial. A continuidade do crescimento, condicionada principalmente ao desenvolvimento econômico, depende ainda de melhores investimentos em qualificação profissional nos mais diversos segmentos. Essa qualificação, invariavelmente, passa pelo ensino superior (CM CONSULTORIA, 2011, p. 5).

5 Para o curso de doutorado, ainda não existe uma tipificação quanto ao número de créditos (IACOBUCCI, 2012). 
Essas defesas pela educação, pautadas nos princípios da modernidade, apresentam-se discursivamente como um padrão operante. Assim, além da padronização da organização educacional, há um discurso homogêneo para perceber a educação de nível superior. Auxiliam-se, desse modo, todos os elementos constitutivos do pensamento there's no alternative diante da educação e do mundo. Na dinâmica educacional, as defesas visam "[...] instituir um novo padrão de convergência entre instituições e cursos em meio ao acirramento da competitividade global" (FERREIRA, 2009, p. 35).

Assim, foram considerados dois aspectos sobre a padronização do programa UAB: a estrutura e o atendimento às demandas econômicas nacionais e, principalmente, internacionais. A UAB padroniza seus cursos na maneira didático/pedagógica do formato que propõem, que engloba: o trato com o conheicmento, a contratação de tutores, a relação virtual aluno/professor e as coordenações de polo. Ao diminuir a probabilidade dos alunos de terem contato com outros dois elementos que constituem a universidade, ou seja, a pesquisa e a extensão, a UAB homogeneíza a formação profissional pragmática que serve, dentre outras possibilidades, para alcançar níveis e indicadores pré-requeridos pelos $\mathrm{OM}$.

\section{CONSIDERAÇÕES FINAIS}

Os modelos de gestão contemporâneos, que advogam a necessidade de se render mais (lucro) com menos (investimento), expandem-se para todas as relações de trabalho. Conceitos como efetividade, eficiência, rapidez, eficácia, proatividade, resiliência, autonomia e qualidade resumem bem os pressupostos de padronização, mensuração de resultados e outros objetivos observados ao aproximar o PB à UAB.

A estratégia identificada na analise das relações entre PB e UAB demonstrou que, para se produzir consensos, não basta a incorporação de novos termos e slogans. Isto é, faz-se necessária a adoção de novas práticas, de modo a formar um novo homem coletivo, conformado e aberto às transformações propostas pelo neoliberalismo.

Não há como negar que a oferta e a procura pelo ensino a distância vem crescendo consideravelmente no Brasil. Com isso, a UAB, por sua característica pública, torna-se uma espécie de modelo a ser seguido. 
Como foi possível constatar, neste estudo, tal modelo teve como inspiração o processo conhecido como internacionalização da educação que teve, por sua vez, como um dos pilares fundamentais, o Processo de Bolonha.

Ao estabelecer-se a proposta de governança, o Estado passa a gerir a educação com base nas necessidades do mercado financeiro, o que recai sobre a própria educação que se transforma em mercadoria. Tanto na UAB como no PB, observou-se que o verdadeiro arquiteto das propostas não é o Estado, mas as instituições 'públicas-não-estatais' privadas que conduzem a política e, muitas vezes, a governabilidade de um país.

É nesse terreno de internacionalização da educação, pautada na lógica financeira do capital, que a UAB nasceu e se consolidou como um programa voltado a massificar uma modalidade de ensino que, cada vez mais, mostra-se favorável ao atendimento das necessidades dominantes. Cabe destacar que a proposta de ensino a distancia não se constitui no problema central, mas o que se tem objetivado com tal modalidade é que esta deve ser objeto de discussões e pesquisas mais aprofundadas e críticas. Por fim, destaca-se que a hipótese inicial deste trabalho se mostra efetiva uma vez que o PB serve de modelo para que diversas reformas, políticas e ações sejam implementadas, assim como foi o caso da UAB.

\section{REFERÊNCIAS}

ANDRADE, F. A. A formação do "cidadão-trabalhador": educação e cidadania no contexto do "novo industrialismo. In: NEVES, L.M.W. (Org.). Educação e política no limiar do século XXI. Campinas: Autores Associados, p. 59-78, 2008.

BANCO MUNDIAL. Governance and development. Washington, Oxford University Press. p. 1-27, 1992. Disponível em: < http://www-wds.worldbank.org/ external/default /WDSContentServer/WDSP/ IB/1999/09/17/000178830_98101911081228/Rendered/PDF/multi_ page.pdf > . Acesso em: 05 abr. 2018.

BIANCHETTI, R. G. Modelo neoliberal e políticas educacionais. São Paulo: Cortez, 1996. 118 p.

BIANCHETTI, L. O processo de Bolonha e a Globalização da educação superior: antecedentes, implementação e repercussão no que 
fazer dos trabalhadores da educação. Campinas: Mercado das Letras, 2015. $135 \mathrm{p}$.

BORES, A. Governança e política educacional. In: Revista Brasileira de Ciências Sociais, São Paulo, v. 18, n. 52. p. 125-138, jun. 2003. Disponívelem: < http://www.scielo.br/scielo.php?pid = S0102-6909200 $3000200007 \&$ script $=$ sci_abstract $\&$ th $\mathrm{g}=\mathrm{pt}>$. Acesso em: 04 abr. 2018.

BRASIL. Decreto $\mathbf{n}^{0} \mathbf{5 . 8 0 0}$, de 08 de junho de 2006. Dispõe sobre o Sistema Universidade Aberta do Brasil - UAB. 2006. Disponível em: < http://www.planalto.gov.br/ccivil_03 /_ato2004-2006/2006/decreto/d5800.htm > . Acesso em: 21 mar. 2018.

BRASIL. Ministério da Educação. Fórum das Estatais pela Educação. Projeto: Universidade Aberta do Brasil. 13p. 2005. Disponível em: $<$ http://portal.mec.gov.br/arquivos/pdf/universidade.pdf > . Acesso em: 24 mai. 2018.

BRASIL. Ministério da Educação. O Plano de Desenvolvimento da Educação. Razões, Princípios e Programas. Brasília, DF, MEC, 2007a. Disponível em: < http://portal.mec.gov.br/arquivos/livro/ livro.pdf > . Acesso em: 10 jun. 2018.

BRASIL. Ministério da Educação. Secretaria de Educação a Distância. Referenciais de qualidade para educação superior a distância. 31p. 2007b. Disponível em: < http://portal.mec.gov.br/seed/arquivos/ pdf/legislacao/refead1.pdf > . Acesso em: 03 abr. 2018.

BRASIL. Palácio do Planalto. Fórum das Estatais pela Educação; diálogo para a cidadania e inclusão. 2004. Disponível em: < http://portal. mec.gov. br/arquivos /pdf/texto.pdf > . Acesso em: 15 mar. 2018.

BRESSER-PEREIRA, L. C. Gestão do setor público: estratégia e estrutura para um novo Estado. In: BRESSER-PEREIRA, L. C.; SPINK, P. K. (Org.). Reforma do Estado e Administração Pública Gerencial. Rio de Janeiro: Fundação Getúlio Vargas, p. 21-38, 1999. Disponível em: < http://www.plataformademocrati ca.org/Publicacoes/7562_ Cached.pdf > . Acesso em: 03 mar. 2018.

CATANI, A. M. Processo de Bolonha e impactos na América Latina: incursão preliminar em produções bibliográficas recentes. In: Apresentação ANPAE Ibero Americana. Elvas. Portugal. abr. 2010. p. 1-14. Disponível em: <http://www.an pae.org.br/iberoluso brasileiro2010/cdrom/4.pdf > . Acesso em: 14 jun. 2018.

CHESNAIS, F. A mundialização do capital. Tradução: Silvana Finzi Foá. São Paulo: Xamã, 1996, 335 p. 
CM CONSULTORIA. Estudos e projeções: panoramas e propostas. Apresentado no IV Congresso Brasileiro da Educação Superior Particular. Salvador: CM Consultoria, 2011, 204 p. Disponível em: < http://www.abmes.org.br/abmes/documentos/visualizar/ id/48 > . Acesso em: 03 mar. 2018.

COMUNICADO DE BERGEN. The European Higher Education Area Achieving the Goals. 2005. Disponível em: < http://www.uc.pt/ ge3s/pasta_docs/outros_docs/com un_bergen $>$. Acesso em: 30 abr. 2018.

COMUNICADO DE LEUVEN/ LOUVAIN-LA-NEUVE. The European Higher Education Area in the new decade. 2009. Disponível em: < http://www.uc.pt/ge3s/pasta_guia_ ge3s/Leuven _Louvain-la-Neuve_Communiqe29_April_2009.pdf > . Acesso em: 20 mai. 2018. COMUNICADO DE LONDRES. Towards the European Higher Education Area: responding to challenges in a globalised world. 2007. Disponível em: < http://www. uc.pt/ ge3s/pasta_docs/outros_ docs/comun_londres > . Acesso em: 20 de mai. 2018.

COMUNICADO DE PRAGA. Towards the European Higher Education Area. 2001. Disponível em: < http://www.uc.pt/ge3s/pasta_docs / outros_docs/comun_praga > . Acesso em: 20 de mai.2018.

DALE, R. Globalização e educação: demonstrando a existência de uma "cultura educacional mundial comum" ou localizando uma "agenda globalmente estruturada para a educação”? In: Educação e Sociedade, Campinas, v. 25, nº 87, mai./ago. 2004. p. 423-460. Disponível em: < http://www.scielo.br/pdf/es/ v25n87/21464.pdf > . Acesso em: 22 de jul. 2018.

DECLARAÇÃo DE BOLONHA. 1999. Disponível em: http://www.ehea. info/ Uploads/Documents/1999_Bologna_Declaration_Portuguese. pdf. Acesso em: 20 mai. 2018.

DECLARAÇÃo DE SORBONNE. 1998. Disponível em:<http://www. fam.ulusiada.pt/downloads/bolonha/Docs01_DeclaracaoSorbonne. pdf > . Acesso em: 20 de abr. 2018.

EUA. Trends V: Universities shaping the European Higher Education Area: an EUA report. Londres. 2007, 100 p. Disponível em: < http:// www.uc.pt/ge3s /pasta_guia_ge3s/Final_Trends_Report_V_May. pdf > . Acesso em: 25 mar. 2018.

FERREIRA, S. A universidade do século XXI: concepções, finalidades e contradições. 2009. 305 f. Tese (Doutorado em Educação) - Universidade Federal de Goiás, Goiânia, 2009. 
GRAMSCI, A. O leitor de Gramsci: escritos escolhidos 1916-1935. COUTINHO C. N. C. (Org.). Rio de Janeiro: Civilização Brasileira, 2011, $375 \mathrm{p}$.

IACOBUCCI, G. O Processo de Bolonha: um modelo europeu de reforma do ensino superior? - O impacto nas outras regiões do mundo (o caso da América Latina e do Brasil). 2012. 133 f. Dissertação (Mestrado em Estudos Europeus), Faculdade de Letras da Universidade de Coimbra, Coimbra, 2012.

LIMA, F. P. A. Medida e desmedida: padronização do trabalho livre ou livre organização do trabalho vivo?. In: FIDALGO, F. S. (org.) Gestão do trabalho e formação do trabalhador. Belo Horizonte: Movimento de Cultura Marxista, p.109-130, 1996; Disponível em: < http:// www.scielo.br/pdf/prod/v4nspe/v4 nspea01.pdf > . Acesso em: 05 mar. 2018.

LIMA, L.C.; AZEVEDO, M. L. N.; CATANI, A. M. O processo de Bolonha, a avaliação da educação superior e algumas considerações sobre a universidade nova. In: Avaliação, Campinas, v. 13, n. 1, mar. 2008. p. 7-36. Disponível em: < https://ape.unesp.br /pdi/execucao/artigos/avaliacao/a02v13n1.pdf > . Acesso em: 10 abr. 2018.

LIRIA, C. F.; GARCÍA, C. S. El plan Bolonia. Madri: Catarata. 2009, $104 \mathrm{p}$.

MORGADO, J. C. Processo de Bolonha e ensino superior num mundo globalizado. In Educação e Sociedade, Campinas, v. 30, n. 106, p. 37-62, jan/abr. 2009. Disponível em: < http://www.scielo.br/pdf/ es/v30n106/ v30n 106a03.pdf > . Acesso em: 05 mai. 2018.

NEVES, L. M. W.; PRONKO, M. A. O mercado do conhecimento e o conhecimento para o mercado, da formação para o trabalho complexo no Brasil contemporâneo. Rio de Janeiro: EPSJV, 2008.

RUIZ, R. El proceso de Bologna, cuatro años después. In: Pró - Posições, Campinas. v. 15, n. 3(45), p. 21-36, set/dez. 2004. Disponível em: < https://www.fe.unicamp.br/lan camentos/2274 >. Acesso em: 16 jun. 2018.

UE. Jornal Oficial da União Europeia: Informações das instituições, órgãos e organismos da União Europeia. Conclusões do Conselho sobre a dimensão global do ensino superior europeu. IV Informação. 4 p. Publicado em 31 de janeiro de 2014. Disponível em: < http://www.igfse.pt/upload/docs/2014/2014_C28_03.pdf > . Acesso em: 16 mai. 2018. 
